\title{
Fracaso escolar, crisis económica y desigualdad de oportunidades educativas: España y Argentina
}

\author{
José Saturnino Martínez García \\ Universidad de La Laguna. Departamento de Sociología y Antropología \\ josamaga@ull.es \\ ORCID 0000-0002-8688-0293
}

\section{Pablo Molina}

Universidad de Buenos Aires e Instituto de Investigaciones Gino Germani pablomd2009@gmail.com

ORCID 0000-0002-6882-0553

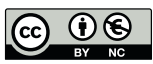

Recepción: 17-04-2018

Aceptación: 08-08-2018

Publicación: 13-03-2019

\section{Resumen}

El objetivo del presente trabajo es analizar el efecto de las crisis económicas en la desigualdad de oportunidades educativas, comparando el logro educativo de familias españolas y argentinas. El indicador elegido es el fracaso escolar administrativo, definido como no obtener el título mínimo requerido en el sistema educativo. Estos efectos se circunscriben al efecto renta, por el cual, ante un descenso de los ingresos en los hogares, se incrementa el mencionado fracaso, y al efecto sustitución, por el cual el empeoramiento del mercado de trabajo disminuye los costes de oportunidad y hace que la opción de la escolaridad sea más atractiva.

Los datos utilizados comparan años anteriores y posteriores a la crisis económica de 2008 y toman como población a los jóvenes de 19 y 20 años, residentes en Argentina y España. La variable dependiente es el fracaso escolar, y como variable independiente se toma el nivel de estudios del hogar, la situación de inmigración, y variables para modelizar la situación económica. Se estiman regresiones logísticas separando por sexo y país, y con interacciones con el año de crisis. Los resultados sugieren que en España prevalece el efecto sustitución, y en Argentina, el efecto renta, sin que la crisis produzca cambios estructurales significativos en la relación que hay en cada país entre el origen social y el fracaso escolar.

Palabras clave: desigualdades de oportunidades educativas; crisis económica; fracaso escolar; capital humano

* Este artículo ha sido elaborado en el contexto de la Red Internacional para el Estudio Comparado de la Desigualdad Social (International Network for Comparative Analysis of Social Inequalities Network, INCASI), proyecto que recibe fondos de la Unión Europea Horizon 2020 Research and Innovation Programme under the Marie Skłodowska-Curie GA No 691004, coordinado por Dr. Pedro López-Roldán. Este artículo solo refleja la opinión de sus autores y la Agencia no es responsable de los usos que se puedan hacer con la información que contiene. 
Abstract. School failure, economic crisis and inequality of educational opportunities: Spain and Argentina

The objective of this paper is to analyse the effect of economic crises on the inequality of educational opportunities through a comparison of the performances of Spanish and Argentine families. The chosen indicator is administrative school failure, defined as not achieving the minimum qualification required in the education system. These effects are limited to the income effect, by which, faced with a decline in household income, school failure increases; and to the substitution effect, by which poor labour market performance makes the option of schooling more attractive. The data compare the years prior to and after the economic crisis of 2008 with a population of young people aged 19 and 20 years old living in Argentina and Spain. The dependent variable is school failure, and as an independent variable we take the level of education of the household, the immigration situation and variables to model the economic situation. The models are estimated by sex and country and by interactions with the crisis year. The results show that the substitution effect prevails in Spain, whereas the income effect prevails in Argentina, with no structural changes between social origin and school failure being detected in either country.

Keywords: inequality of educational opportunities; economic crisis; school failure; human capital
Sumario
1. Introducción
2. Ciclo económico y escolarización
3. El fracaso escolar administrativo
4. Las crisis económicas
5. Datos y operacionalización de variables
6. Modelos multivariantes
7. Conclusiones
Referencias bibliográfica

\section{Introducción}

La introducción de la educación masiva y obligatoria en las sociedades modernas tiene algunos efectos no intencionados. Uno de ellos es que ha ayudado a evidenciar las desigualdades de oportunidades educativas que existen entre los diferentes estratos sociales, y que la gratuidad y obligatoriedad no necesariamente logran subsanar. La educación obligatoria y gratuita se ha implantado de forma efectiva en ambos países, reforzada por la legislación que prohíbe el trabajo de los menores mientras la cursan. Pero este esfuerzo público y legislativo no es suficiente para eliminar todo impedimento para lograr el nivel de escolarización mínimo que marca la ley. Por un lado, hay que tener en cuenta los costes directos e indirectos de estudiar, así como los posibles costes de oportunidad derivados de actividades económicas que incumplan la prohibición de trabajar de los menores. Por otro lado, las desigualdades en capacidad individual y capital cultural de las familias, que hace que los esfuerzos para lograr el currículum mínimo necesario para lograr el título educativo sean diferentes.

Los ciclos económicos suponen modificaciones en los flujos de ingresos y en la inserción laboral de los miembros activos del hogar. En casos de crisis de ingresos y/o empleo, esto sitúa los hogares de menores recursos en la disyun- 
tiva de integrar o no en forma temprana a miembros del hogar que estarían cursando educación secundaria. Estas mismas crisis pueden también tener otras repercusiones que incluyan formas de conflicto y anomia que lleven a la deserción y al fracaso escolar (Leivas, 2017). Este artículo no indaga acerca de las motivaciones a nivel de la unidad del hogar, sino que se interroga, en forma agregada, acerca de la relación existente entre ciclos económicos y desigualdad de oportunidades educativas.

La relación entre ciclo económico y desigualdad de oportunidades educativas es indeterminada, en la medida que intervienen relaciones causales de signo contrario, como son el efecto renta y el efecto sustitución, y por tanto el efecto neto dependerá de la intensidad de cada una de estas fuerzas. Un interrogante que se plantea, entre tantos posibles, es cuál es la influencia que podría tener una crisis económica en las oportunidades educativas de los jóvenes, a la luz de las estrategias de los hogares. Como ejemplo ilustrativo, se presenta un análisis comparativo entre el fracaso escolar administrativo en España y Argentina, dos países con ciclos ascendentes y crisis económicas durante la primera década del siglo XXI, pero con contextos socioeconómicos y políticos muy diferentes. Mediante el empleo de regresiones logísticas, se procede a detectar los patrones similares, así como las diferencias en los efectos de las crisis sobre la desigualdad de oportunidades educativas.

\section{Ciclo económico y escolarización}

Para abordar la complejidad de las relaciones entre ciclos económicos y desigualdad de oportunidades educativas, se pasa a revisar investigaciones previas, teniendo en cuenta tanto reflexiones más generales como la evidencia empírica disponible. Es oportuno señalar, como afirma Carabaña (2018), que las relaciones entre ciclos económicos, oportunidades educativas y las decisiones de los hogares no son lineales, es decir, que una variación en cierto sentido del crecimiento económico no se transmite de forma mecánica a una cierta variación de las oportunidades educativas o a la demanda de educación, pues cada uno de sus ámbitos obedece a sus propias lógicas, y la interacción entre ellas produce resultados que no son fáciles de anticipar, por lo que es necesario considerar de forma conjunta el curso del ciclo económico con los determinantes socioeconómicos y culturales de las familias.

En un nivel más abstracto, se puede partir de las líneas generales de los enfoques del capital humano, por el cual la educación reglada de los miembros más jóvenes de los hogares - obligatoria y no obligatoria - es vista como una inversión a la que destinar recursos (tiempo, dinero, etcétera), así como hacer frente al coste de oportunidad: por dedicar recursos a los estudios en los niveles medio y superior en lugar de una «temprana» inserción en el mercado de trabajo. A su vez, se destacan otros planteamientos que ponen en consideración que la decisión de continuar la escolarización en niveles cada vez más altos depende también del capital cultural acumulado en el núcleo conviviente, que implica valoraciones diferenciales acerca de si es «conveniente» la dedica- 
ción a estudios superiores, e incluso la finalización de los estudios medios. Sin embargo, estos razonamientos deben ser sopesados en un contexto histórico de expansión educativa, en el que el incremento de la oferta de plazas educativas y la obligatoriedad legal efectiva de cursar estudios pueden debilitar el efecto del capital cultural del hogar sobre el éxito educativo en los niveles más bajos.

En este artículo se analizan en forma comparativa los efectos de los choques agregados (Peña, 2013), es decir, las crisis macroeconómicas, definidos como cambios de las condiciones económicas agregadas de los países de magnitud tal que obligan a gran parte de los hogares a redefinir sus estrategias económicas, y por tanto de inversión en educación. Frente a un choque agregado (una reducción del producto interior bruto), se plantean opciones contrarias agrupadas en efecto renta y efecto sustitución (Dellas y Sakellaris, 2003). El efecto renta se debe a que, con las crisis, disminuye el poder adquisitivo de las familias, y por tanto su capacidad de demandar educación. Cuanto mayor sea el descenso de ingresos de la familia, cabe esperar que menor será la posibilidad de que haya personas estudiando en dicha familia. Esta relación estará mediada por el peso de las restricciones presupuestarias de las familias en los estudios.

Por otro lado, está el efecto sustitución, que, resumiendo, podríamos decir que consiste en sustituir empleo por estudios. Es decir, que a medida que se destruye empleo, aumenta la demanda de educación, pues disminuye el coste de oportunidad de estudiar: cuanto más difícil es encontrar empleo o/y más bajos son los salarios, menos se pierde por seguir estudiando. De esta forma, la coyuntura laboral pasa a ser un factor importante para entender las variaciones en la demanda de educación.

El citado estudio de Peña sugiere que los efectos renta y sustitución no se dan en igual proporción. Los estudios de DeJong e Ingram (2001), Dellas y Sakellaris (2003) y Carabaña (2018) encontraron que predominaba el efecto de sustitución en los países más desarrollados; y que los efectos resultantes no eran lineales con los diferentes estratos sociales. A su vez, estudios como el de Rodríguez y Lacasa (2018) aportan evidencia comparativa en la que muestran que los países pueden presentar divergencias ante las crisis económicas, según los distintos modelos de expansión educativa y la intensidad de los ciclos económicos. Si a estos argumentos añadimos lo que sostiene Peña (2013), queda clara la necesidad de estudios comparados entre países europeos y latinoamericanos, pues dado que las diferencias entre estas economías son considerables, nos pueden ayudar a entender mejor la lógica propia de reproducción educativa de las familias, más allá de las variaciones económicas e institucionales.

En el caso de América Latina, la literatura presenta algunas variaciones sobre los efectos renta y sustitución. Siguiendo la línea del primero, podríamos mencionar la llamada tesis de trabajador adicional (Paz, 2014; Molina, 2007), en la que se sostiene que los principales sustentadores de familias pobres y vulnerables poseen ingresos muy bajos y deben incorporar a otros miembros como trabajadores secundarios. Es decir, trabajadores que aportaran un ingreso suplementario al exiguo ingreso del principal sostén de hogar, pero ingreso necesario para evitar que el hogar caiga en situación de mayor pobreza y/o 
indigencia. Para las cónyuges — mayormente mujeres—, se trata de dedicar menos tiempo al trabajo doméstico no remunerado; para los jóvenes y adolescentes, la interrupción de los estudios (Paz, 2014; Beccaria y Groisman, 2005 y 2015; Gutiérrez y Uanini, 2015; Busso y Pérez, 2015; Sánchez, 2018). Dicho en otros términos, el comportamiento económico cíclico supone una dura prueba para algunos hogares que no pueden afrontar el «lujo» de no emplear a sus hijos en edad escolar en una ocupación remunerada, la cual por las propias características de los jóvenes es de baja calidad e ingresos.

$\mathrm{Al}$ referirse al efecto de sustitución, estudios en países latinoamericanos enfatizan que las crisis económicas en sus ciclos descendentes suelen destruir mayormente los empleos de baja productividad, que serían, precisamente, aquellos a los que la juventud que abandona la escuela podría acceder. Ante esta imposibilidad, cursar estudios secundarios se vuelve una opción no solo como supuesta inversión en educación, sino también como búsqueda de ambientes de contención y socialización de la población joven, para evitar patrones de marginalidad y exclusión social (Puiggrós, 2014; Rocha, 2016; Vezub y Garabito, 2017).

Considerando la literatura aquí presentada, se plantea en este trabajo un análisis comparativo entre Argentina y España para dar cuenta de cuál de ambos efectos (renta o sustitución) prevalece a nivel agregado del país en una crisis económica, como aconteció con las réplicas en España y Argentina resultantes de la conocida como Gran Recesión, iniciada en 2008, o crisis derivada de las hipotecas subprime en los Estados Unidos, que contagió al conjunto de la economía mundial.

La premisa subyacente en los estudios que buscan encontrar la asociación entre variaciones en el ciclo económico y cambios en la demanda de escolarización es que tal choque económico afecta de forma diferente a los hogares según su posición social e incide en mayor medida en las decisiones educativas de los hogares de clase social más baja. En los párrafos precedentes se han visto los efectos de la crisis sobre la demanda de educación para el conjunto de la población, pero se ha pasado a la cuestión de su efecto sobre la desigualdad de oportunidades educativas. Este problema ha sido menos estudiado, pues la sociología ha abordado especialmente el problema de la desigualdad de oportunidades (Fernández Mellizo-Soto, 2015), y la economía, el de las crisis (Clark, 2011; Peña, 2013; Sievertsen, 2012 y 2016). Los estudios que tienen en cuenta ambos problemas son limitados (Carabaña, 2018; Lacuesta et al., 2012; Rodríguez y Lacasa, 2018; Torche, 2010). Estos estudios prestan atención al contexto concreto de la situación en la que se producen las crisis, por lo que debemos tener en cuenta los niveles previos de escolarización, los niveles absolutos de renta previos a las crisis y la incidencia de las crisis sobre el sistema educativo, así como que los efectos pueden ser diferentes, dependiendo del nivel educativo y de si hablamos de formación profesional o académica, ya sea media o superior.

En el contexto argentino, donde la renta es considerablemente menor, debe tenerse en cuenta además que las crisis y las desigualdades educativas se 
manifiestan de formas más diversas que la interrupción de la asistencia escolar. Algunos de los efectos incluyen la profundización de la distancia entre escuela públicas y privadas (inclusive las subvencionadas — concertadas-), donde los contextos de crisis hacen que los hogares de sectores medios «migren» de la educación privada a la pública, que perciben como de menor calidad (Grimson y Tenti Fanfani, 2014; Gottau y Moschetti, 2017; Martín, 2018), mientras que en España ha permanecido constante el porcentaje de alumnado matriculado en centros públicos (en el entorno del 67\% a 68\% desde el curso 2000/2001 hasta el curso 2016/2017, con poca diferencia con respecto a años anteriores). Incluso pueden acentuarse situaciones conflictivas, incluyendo acoso escolar y discriminación (Núñez y Litichever, 2016; Molina Derteano, en prensa). Estos efectos sirven para considerar que no resulta tan lineal la experiencia escolar para los hogares y que no puede ser reducida, en el caso argentino, a una preparación para el mercado de trabajo y/o la vida adulta en general, sino que es una relación compleja donde la escolarización y su abandono están teñidos por dinámicas que se retroalimentan. A esta complejidad, se le suma además el desafío de la comparación internacional, razón por la cual en esta investigación simplificamos parte del problema centrándonos en el fracaso escolar.

Si enlazamos estas consideraciones con los debates más clásicos de la sociología de la educación generados en los sesenta, se aprecia que la crisis puede ser una forma de confrontar las principales tradiciones de sociología de la educación (Martínez García, 2011). Por un lado, están funcionalistas y neoweberianos, que toman la escuela como una caja negra en la que se vienen a reflejar las desigualdades sociales que existen fuera de ella, sin que dicha institución intervenga especialmente en aumentarlas o atenuarlas. Y por otro lado, la sociología crítica, que incide en los aspectos en que la escuela contribuye a reproducir las desigualdades sociales, debido a su sesgo favorable a las clases sociales medias y altas. La crisis, al ser un cambio tan rápido de las condiciones económicas, sirve para calibrar el peso de factores extraescolares en contra de los factores propiamente escolares de tipo cultural (habitus de clase social y género, subcultura escolar...), cuyo cambio es más lento, y deja de lado el «efecto tijera» (es decir, los recortes en inversiones públicas dedicadas a la educación, como diferente al efecto renta, debido a la diminución de la renta de las familias) y sus influencias negativas (Martínez García, 2019). El efecto sustitución está bien teorizado desde el punto de vista de Boudon (1983), pero no tanto desde el punto de vista de Bourdieu, debido a que el primero lo recoge como «efectos secundarios» (coste de oportunidad), mientras que Bourdieu hace más hincapié en los factores culturales. Tales factores, por su propia naturaleza, tienden a ser más inerciales y difíciles de cambiar por cuestiones coyunturales como una crisis económica. Pero eso no quita la posibilidad de que, de ser esta persistente, pueda afectarles, en tanto que la idea de habitus de Bourdieu incorpora a la perspectiva de los actores las probabilidades objetivas como un horizonte de probabilidad sentido como realista (Bourdieu, 1991; Martínez García, 2017a).

Puede decirse que el enfoque del individualismo metodológico de tipo neoweberiano es de algún modo tributario de una concepción de tipo eco- 
nomicista que apela a la racionalidad instrumental del coste y el beneficio, en alguna de sus interpretaciones (Martínez García, 2004). Sin embargo, en América Latina hay una importante tradición de estudios sobre las estrategias de los hogares y en qué medida la escolarización de sus miembros es parte de dichas estrategias destinadas a la reproducción y/o a la expansión de las condiciones de vida del hogar (Torrado, 1981; Salvia, 2000; Fiszbein et al., 2003). El debate abarca los grados de definiciones de racionalidad de los decisores en los hogares e intenta desentrañar cómo se valoriza según el capital cultural (Katzman, 2005; Gutiérrez, 2005; Molina Derteano y Dávolos, en prensa).

Además, debe tenerse en cuenta que los efectos renta y sustitución pueden implicar prácticas diferentes en una misma familia. Un hogar podría, por ejemplo, considerar enviar a los varones al mercado de trabajo y a las mujeres a la escuela (Molina Derteano, 2012); de manera que el género incidiría de formas diferentes, pues las oportunidades laborales para las mujeres sin estudios son peores que para los varones (Molina Derteano, 2012; Martínez García, 2005 y 2011). Muchas de estas consideraciones, a nuestro juicio, implican análisis comparativos entre los diferentes estratos y hogares, a la vez que entre los diferentes países. Sin embargo, para este artículo, la idea es comenzar por un paso previo, que es observar en forma comparativa el efecto de la crisis en España y Argentina.

Finalmente, no se debe dejar de tener en cuenta que, producto de la crisis, hubo en España una disminución de la inversión pública en educación, del orden de un 25\% por estudiante entre 2008 y 2014 (Martínez García, 2016), descontada la inflación, mientras que en Argentina, entre 2005 y 2009, crece un 41\%, después de alcanzar su valor más bajo desde 1998 (Rivas y Dborkin, 2018). El recorte en el caso de España ha incidido de diversas formas: disminución de salarios del profesorado, incremento de la ratio alumnado/profesorado, eliminación de programas de apoyo a los centros, diminución de las partidas dedicadas a la inversión y mantenimientos de infraestructuras y servicios educativos... Cabe esperar que el efecto causal de cada uno de estos recortes pueda ser diferente sobre la tasa de fracaso escolar. El aumento en Argentina parece haberse dedicado mayormente a salarios del profesorado, con menos impacto relativo en infraestructura y material didáctico, a pesar de iniciativas como el programa Conectar Igualdad. Son factores que no se deben soslayar, ya que la inversión pública y la oferta de educación obligatoria gratuita son elementos importantes de disminución de las desigualdades formales y de acceso.

\section{El fracaso escolar administrativo}

El fracaso escolar es una expresión polisémica, tomada del debate de la política educativa (Bernard, 2015; Rujas, 2015). Dicha expresión data en España de la expansión generalizada de la ampliación de la edad de escolarización obligatoria que supuso la Ley General de Educación (LGE) de 1970. Su empleo como estigma y forma de culpabilizar al alumnado ha hecho que se convierta en poco adecuada, y hay autores que proponen sustituir la expresión por otras 
más precisas, pero demasiado complejas, por lo que no se han hecho populares (Marchesi, 2003). Son muchas las formas de operacionalizarlo, y cada una de ellas lleva acompañada el análisis sobre dimensiones diferentes del proceso educativo. La definición puede hacer más hincapié en la adquisición de competencias (cognitivas y no cognitivas), de contenidos curriculares, en el logro de la titulación mínima del sistema educativo... No debería confundirse con el abandono educativo temprano (AET), un indicador de Eurostat, que, al mezclar titulación y cursar estudios, es poco aconsejable para entender la dinámica de los procesos educativos, ya que ambas dimensiones entrañan procesos causales diferentes (Carabaña, 2016; Martínez García, 2016). En aras de la precisión, claridad analítica y comparabilidad, en esta investigación optamos por el fracaso escolar administrativo (FEA). Con esta expresión, se hace referencia a no lograr el título mínimo requerido en el sistema educativo, que actualmente en España es el de Graduado en Educación Secundaria Obligatoria (GESO) (Martínez García, 2017b) y en Argentina el Secundario completo. La idea de «administrativo» incide en que depende de la Administración fijar los mínimos necesarios para lograrlo. Por ejemplo, en España se ha pasado de necesitar tener todas las asignaturas aprobadas a permitir dos suspensos, siempre que no sean conjuntamente Lengua y Matemáticas, y se ha barajado la posibilidad de que para lograrlo sea necesario aprobar un examen tras su finalización. Además, se ha comprobado que en dicho país hay variación en la exigencia al alumnado a la hora de otorgar el título, tanto entre comunidades autónomas (Carabaña, 2004; Martínez García, 2012) como entre centros educativos (Tarabini et al., 2015). Dicho de otra forma, esta aproximación tiene en cuenta la arbitrariedad de la Administración educativa (el legislador, los poderes ejecutivos implicados en educación, la inercia institucional de regiones y centros, el profesorado...) a la hora de conceder el título educativo que supuestamente refleja un nivel mínimo de competencias y conocimientos. Además, debe resaltarse que los efectos de no contar con el título son muy variables, tanto entre países como en un mismo país a lo largo del tiempo, por lo que el interés en lograr el título puede estar condicionado al acceso que da a ciertas posiciones, ya sea en el sistema educativo o en el mercado de trabajo. Por ejemplo, en España, con la LGE, ante la situación de fracaso escolar administrativo se podía cursar la FP I, luego la FP II y acceder posteriormente a la universidad. Con la Ley Orgánica de Ordenación del Sistema Educativo (LOGSE 1990) y la Ley Orgánica de Educación (LOE 2006), sin el título, no había paso directo a ningún nivel educativo postobligatorio, situación que ha variado la Ley Orgánica de Mejora de la Calidad de la Educación (LOMCE 2013), que, como la LGE, permite de nuevo el acceso a la FP sin necesidad del GESO, mediante la FP Básica.

En Argentina, considerando la Ley Federal de Educación —ley 24.195 de $1993^{1}$ —, la llamada Educación General Básica (EGB) se dividía en tres tramos,

1. En rigor, debe considerarse todo el proceso. A la Ley Federal de Educación (24.195) se le deben la suma de leyes de transferencia de servicios educativos de nivel medio y superior no universitario de la nación a las provincias y a la entonces municipalidad de la Ciudad de 
comenzando con el Preescolar a partir de la edad de 5 años. El último tramo, llamado EGB 3 abarcaba el séptimo, octavo y noveno grado. A partir de su terminación, comenzaba el Ciclo Polimodal, que no era obligatorio y tenía diferentes orientaciones. La EGB cubría la formación denominada básica y general. A partir de la Ley Nacional de Educación de 2007, el sistema se desarma y regresa a su forma anterior, pero debe armonizar diferencias entre las jurisdicciones, ya que cada provincia tiene competencias propias en el diseño de las trayectorias educativas. Aun cuando haya varias denominaciones y trayectorias, la educación es obligatoria hasta la edad de 17 años, o considerando 13 años de formación a partir del preescolar en la edad de 5 años. En el caso de España, la obligatoriedad es hasta los 16 años de edad.

El fracaso escolar administrativo (FEA) para el caso argentino se define como no finalizar la educación secundaria por dos motivos. El primero es netamente operativo; ante el cambio del sistema de EGB hacia la restitución de la escuela secundaria, la obligatoriedad en los años considerados fue incrementada. En 2005, era hasta EGB 3, es decir, hasta los 14 años, y con la Ley de 2007 la obligatoriedad se extiende hasta los 17. Se armoniza hacia los 17 , en virtud de facilitar la comparabilidad y atendiendo al segundo motivo, que indica que hay evidencia empírica de que los efectos negativos de la no finalización del nivel educativo mínimo se manifiestan con la secundaria y/o polimodal incompleto, sin que incida en modo alguno haber completado el EGB 3. Por estos dos motivos se toma el FEA correspondiente al secundario y/o polimodal en la denominación de la LFE.

El sistema argentino solo otorga la titulación si se han aprobado el total de las asignaturas de todo el trayecto propuesto; algunas de las mismas son correlativas y acumulativas. Si se suspenden hasta dos asignaturas, el alumnado puede pasar al siguiente año. Eventualmente se puede considerar un tercer suspenso, si se trata de una asignatura que no se dicte en el año a continuar.

\section{Las crisis económicas}

Las crisis económicas en Argentina (Ferraris, 2007) y España (Comín y Hernández, 2013; Sebastián, 2015) son de naturaleza muy distinta, y ello debe ser tenerse en consideración al examinar sus efectos. En el gráfico 1 puede apreciarse en el largo plazo la dinámica tan diferente de la economía de ambos países. En los setenta, la economía española da el sorpasso en producto interior bruto (PIB) per cápita a la economía argentina, momento en el que esta entra en un proceso de grandes turbulencias, con ciclos más breves y bruscos que la economía española. Para buscar crisis comparables en magnitud, nos hemos

Buenos Aires - leyes 24.049 y 24.061, sancionadas en 1992, y el decreto 964, de ese mismo año-. Por lo que el proceso se inició al transferir el gasto de la órbita federal a las diferentes provincias, la mayoría de veces sin los recursos que muchas jurisdicciones precisaban para poder hacer frente a estos gastos. Complementa esta secuencia la Ley de Educación Superior - ley 24.521, sancionada en 1995-, que abarca reformas en el nivel superior y superior no universitario. 
Gráfico 1. Evolución del producto interior bruto en España y Argentina, en dólares de paridad de poder de compra

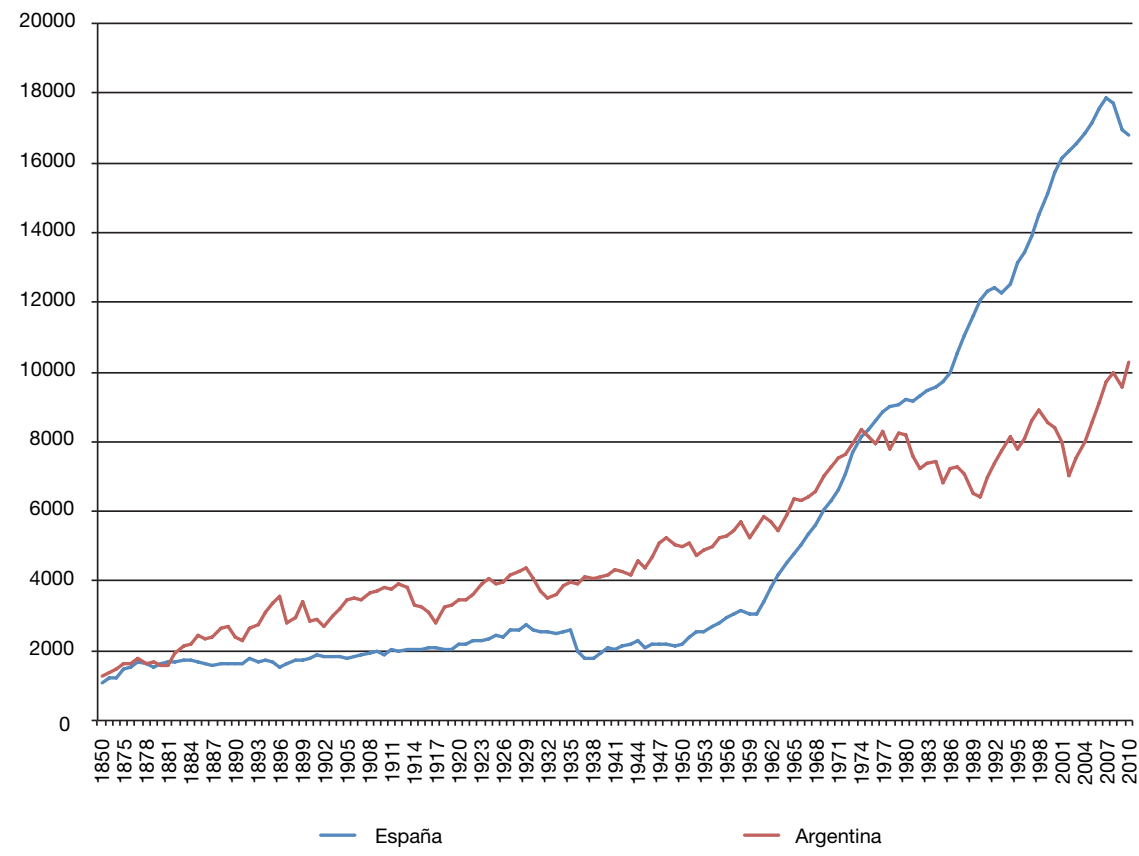

Fuente: base de datos de Angus Maddison (https://www.rug.nl/ggdc/historicaldevelopment/maddison/)

centrado en la más grave (por caída del PIB) en España, que es equivalente a una crisis «normal» de Argentina. En el caso de la economía española, la crisis se debió al efecto de la crisis financiera internacional de 2008, seguida de la crisis del euro iniciada en 2010. El hecho de que muchos de los activos circulando por la economía mundial careciesen de valor en principio no afectó a la economía española, pues las autoridades bancarias habían limitado el acceso a estos productos. Sin embargo, España sufrió sus propios activos tóxicos, debidos a la burbuja de crédito hipotecario (Sebastián, 2015). Por ello, la crisis financiera tuvo un importante efecto sobre la economía real, mediante la destrucción de empleo en la construcción, un sector de cualificación media baja. Casi dos de cada tres desempleados originados con esta crisis provenían del sector de la construcción. En este estudio se compara el momento álgido de la economía española, justo antes del estallido, 2007, con su peor año, 2013.

Argentina tiene un desempeño bastante diferente. En primer lugar, puede verse en el gráfico 1 que el crecimiento del PIB per cápita evoluciona en forma de serrucho, con crecimientos y retrocesos. En 2002, se da una crisis intensa que lleva a una caída profunda del PIB. La gran crisis de fines de 2001 resulta de una combinación de elevado déficit fiscal, empobrecimiento generalizado 
de los sectores medios y bajos, crecimiento del desempleo y el subempleo resultante de la aplicación de reformas neoliberales durante la última década de los noventa. Esta crisis es mayormente endógena, motivada por deficiencias estructurales de la economía nacional, con poca incidencia del factor externo.

A partir de 2003, se inicia un proceso de recuperación económico-social que en 2007 parecía haber alcanzado su punto más alto. Nuevamente al observar el gráfico 1 , se puede ver que Argentina logra superar el nivel de principios de la década de los 70, punto de comparación entre ambos países. Cuando sobreviene la crisis de las hipotecas subprime, el país ya evidenciaba nuevamente signos de estancamiento, agravados por el retroceso en los precios de las materias primas. Como en el caso de España, el mainstream de la crisis internacional no afectó en forma directa, ya que la economía argentina estaba poco vinculada a los flujos financieros internacionales. Hubo un efecto contractivo de la demanda de empleo a partir de 2009 y la economía disminuyó su ritmo de crecimiento, pero no puede decirse que Argentina haya caído en una crisis de las dimensiones que se manifiestan en España u otros países europeos.

Considerando el período, los indicadores de crecimiento son bajos o negativos para los años 2009 (con un leve repunte del desempleo), 2012 y 2014 (que incluyó una devaluación de la moneda y deterioro de los ingresos). En términos comparativos, para España la crisis se desata en 2008 con un rápido deterioro de sus indicadores; para Argentina, se trata de un deterioro más lento y progresivo resultante de la profundización de las limitaciones estructurales de su modelo de crecimiento económico.

\section{Datos y operacionalización de variables}

Para el caso español, tomamos la Encuesta de Población Activa (EPA) de 2007 y 2013. Esta encuesta se realiza por el Instituto Nacional de Estadística (INE), a unos 60.000 hogares, representativa para toda España (INE, 2005). En el caso de Argentina, la muestra corresponde a la Encuesta Permanente de Hogares (EPH), que es elaborada por el Instituto Nacional de Estadística y Censos (INDEC). De estas muestras seleccionamos a personas que en esos años cumplen entre 19 y 20 años de edad. Es una edad en la que la gran mayoría, tanto en España como Argentina, sigue residiendo con su familia de origen, por lo que podemos observar características tanto de sus hogares como de las regiones en las que residen. Dada la naturaleza de la variable dependiente, que es dicotómica, tomaremos como modelo estadístico las regresiones logísticas, ampliamente empleadas en investigaciones tanto sobre demanda educativa como sobre desigualdad de oportunidades educativas.

Como ya señalamos, la variable dependiente es el FEA. Con las variables independientes intentamos modelizar tanto el efecto renta como el efecto sustitución, teniendo en cuenta el origen social. Como indicadores del origen social, tomamos el nivel de estudios de la persona de referencia del hogar, por ser una variable que en otros estudios se ha mostrado como el mejor predictor de rendimiento educativo de los hijos. Nótese el importante descenso de los hogares 
Tabla 1. Estadísticos descriptivos de las variables empleadas en las regresiones logísticas: España

\begin{tabular}{lrrrrrr}
\hline & \multicolumn{4}{c}{ Sexo } \\
\cline { 2 - 3 } & \multicolumn{2}{c}{ Varón } & & \multicolumn{2}{c}{ Mujer } \\
\cline { 2 - 3 } \cline { 6 - 7 } & \multicolumn{2}{c}{ Año } & & \multicolumn{2}{c}{ Año } \\
\cline { 2 - 3 } \cline { 5 - 7 } & 2007 & 2013 & & 2007 & 2013 \\
\hline Tasa de fracaso escolar & 20,5 & 16,2 & & 14,4 & 11,1 \\
Nivel de estudios del sustentador principal & & & & & \\
$\quad$ Sin estudios & 7,1 & 5,4 & & 7,4 & 4,4 \\
$\quad$ Primarios & 25,6 & 18,2 & & 26,1 & 18,4 \\
$\quad$ Secundarios & 53,2 & 59,8 & & 52,6 & 61,6 \\
$\quad$ Universitarios & 14,0 & 16,6 & & 13,9 & 15,6 \\
Extranjeros o nacidos en el extranjero & & 13,5 & & 15,7 & 16,4 \\
Todos los miembros activos del hogar están parados & 7,7 & 5,0 & & 9,7 & 7,7 \\
Tasa de alfabetización (1960) en la CA de residencia & 91,7 & 91,6 & & 91,8 & 91,5 \\
Tasa de paro por comunidad autónoma & 6,6 & 26,4 & & 11,4 & 28,1 \\
\hline
\end{tabular}

Fuente: microdatos de la EPA (INE).

en los que dicha persona no pasa de estudios primarios, como consecuencia de la expansión educativa que experimentaron las personas nacidas entre finales de los sesenta y principios de los setenta, en edad de ser progenitores de los entrevistados. Este descenso podría afectar características no observadas de tal población, pues al disponer de más oportunidades educativas los adultos de 2013 que los de 2007, los que quedan con bajo nivel de estudios pueden contar con características asociadas de forma más negativa con los estudios. Esta variación en la composición del nivel de estudios explica la paradoja de Simpson observada: si bien el FEA aumenta para todos los grupos, disminuye para el total de la población, debido a que disminuye el peso del grupo de más FEA, mientras que aumenta el de menos.

Como efecto renta se tiene en cuenta si la persona de referencia del hogar está en desempleo, mientras que como efecto sustitución tomamos la tasa de desempleo por región (comunidad autónoma en España y aglomerado en Argentina, esto es, un constructo estadístico que tiene en cuenta agrupaciones territoriales en torno a grandes núcleos poblacionales). Debido a que esta tasa se encuentra correlacionada con el nivel de desarrollo regional, y a su vez el desarrollo regional incide en el FEA, se toma el nivel de analfabetismo previo (en 1960) como indicador de desarrollo regional. De esta forma, el elemento regional queda capturado en esta variable, más estable, mientras que la variación coyuntural del mercado de trabajo queda reflejada en el desempleo regional. Además, se controla si la población es de origen inmigrante, pues pudieron darse variaciones en su composición durante la crisis (por haberse ido del país), así como debido a que los procesos educativos a los que se enfrenta son diferentes a la población de origen nacional (ambos progenitores con nacionalidad 
Tabla 2. Estadísticos descriptivos de las variables empleadas en las regresiones logísticas: Argentina

\begin{tabular}{lrrrrrr}
\hline & \multicolumn{3}{c}{ Sexo } \\
\cline { 2 - 3 } & \multicolumn{2}{c}{ Varón } & & \multicolumn{2}{c}{ Mujer } \\
\cline { 2 - 3 } \cline { 6 - 7 } & \multicolumn{2}{c}{ Año } & & \multicolumn{2}{c}{ Año } \\
\cline { 2 - 3 } \cline { 6 - 7 } & 2005 & 2009 & & 2005 & 2009 \\
\hline Tasa de fracaso escolar & 46,6 & 48,6 & & 31,2 & 36,7 \\
Nivel de estudios del sustentador principal & & & & & \\
$\quad$ Sin estudios & 19,9 & 19,0 & & 17,2 & 22,5 \\
$\quad$ Primarios & 61,9 & 59,7 & & 64,8 & 56,3 \\
$\quad$ Secundarios & 14,5 & 17,4 & & 12,4 & 18,7 \\
$\quad$ Universitarios & 3,8 & 3,9 & & 5,6 & 2,5 \\
Extranjeros o nacidos en el extranjero & 5,8 & 4,8 & & 6,3 & 6,2 \\
Todos los miembros activos del hogar están parados & 2,2 & 5,0 & & 3,0 & 3,2 \\
Tasa de alfabetización del aglomerado (promedio) & 92,6 & 92,9 & & 90,4 & 91,2 \\
Tasa de paro por aglomerado (promedio) & 10,3 & 11,9 & & 7,4 & 8,5 \\
\hline
\end{tabular}

Fuente: microdatos de la EPH (INDEC).

española, y entrevistado nacido en España), como prueban algunos estudios (Miyar-Busto, 2017).

Las tasas de FEA en Argentina son mayores, y la situación ha empeorado ligeramente entre 2005 y 2009 , pues ha pasado del $46,6 \%$ al $48,6 \%$ para los chicos y del 31,2\% al 36,7\% para las chicas. Las tasas de alfabetización de los aglomerados (calculadas para los mayores de 18 años) se mantienen casi iguales y hay disminución de la tasa de paro tanto para hombres como mujeres. Dos tercios de los jóvenes varones y en torno a la mitad de las jóvenes provenientes de familias de bajo nivel educativo están en situación de FEA, con una tendencia al aumento en la crisis, que ha sido mayor para las mujeres (del 47,6\% al 58,9\%) que para los varones (del 63,0\% al 70,8\%). Debido a la escasa proporción de jóvenes de familias de estudiantes universitarios, en los posteriores modelos multivariantes esta categoría aparece agregada con estudios secundarios. Aumentan también, aunque en proporción muy leve, quienes muestran fracaso escolar administrativo y provienen de hogares con sostén migrante y donde todos los miembros activos están en paro. Con todo, son variaciones pequeñas.

En el gráfico 2 y en el gráfico 3 se muestran las tasas de FEA españolas para hombres y mujeres, respectivamente, en 2007 y 2013. Se aprecia su aumento para todos los niveles educativos, excepto para quienes provienen de hogares con estudios universitarios. En el caso de los estudios secundarios, tanto para varones como para mujeres, los datos están en el margen de significación estadística. Se puede interpretar que el efecto bruto de la crisis ha sido el del incremento de la desigualdad de oportunidades educativas por nivel de estudios del hogar, especialmente debido al aumento del fracaso escolar entre 
Gráfico 2. Tasas de fracaso escolar administrativo, por año y por nivel de estudios de la persona principal del hogar. Varones residentes en España entre 19 y 20 años de edad

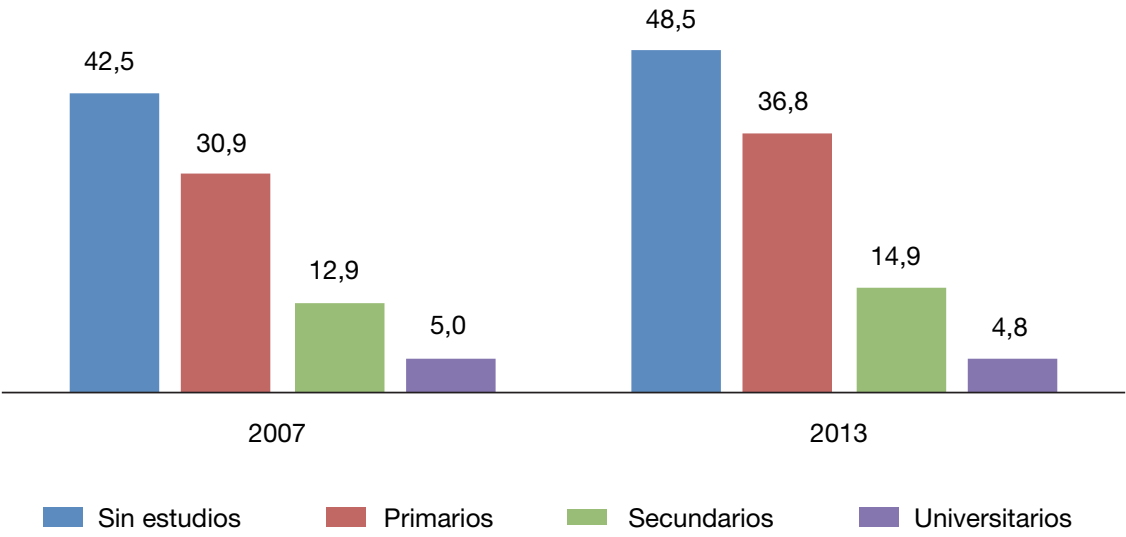

Fuente: microdatos de la EPA (INE).

quienes provienen de hogares sin estudios o con estudios primarios. Queda por averiguar en el siguiente apartado en qué medida estos resultados brutos se deben a cambios coyunturales en el mercado de trabajo o a modificaciones en la relación entre el origen social, medido por el nivel de estudios.

En cuanto a los datos de Argentina, que se encuentran en los gráficos 4 y 5 , uno de los datos que sobresalen es la diferencia entre el porcentaje de FEA de quienes provienen de hogares con secundario incompleto y los demás niveles educativos, donde las proporciones son bastante menores.

Gráfico 3. Tasas de fracaso escolar administrativo, por año y por nivel de estudios de la persona principal del hogar. Mujeres residentes en España entre 19 y 20 años de edad

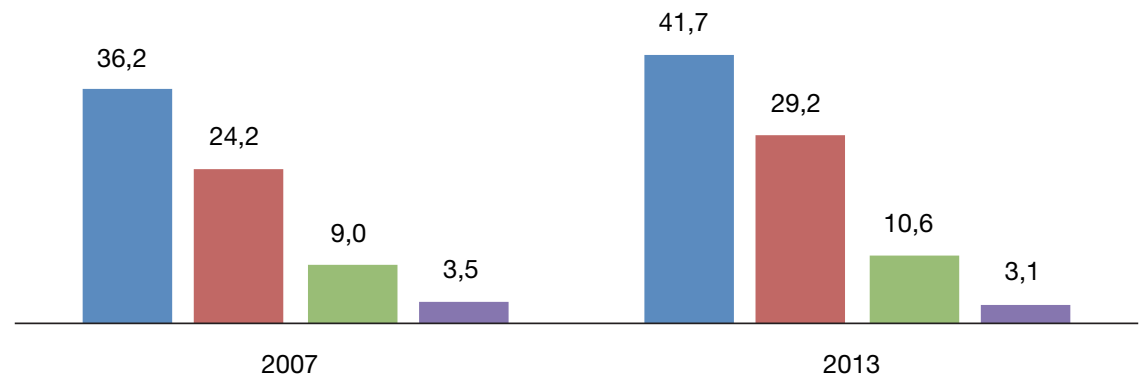

Sin estudios

Primarios

Secundarios

Universitarios

Fuente: microdatos de la EPA (INE). 
Gráfico 4. Tasas de fracaso escolar administrativo, por año y por nivel de estudios de la persona principal del hogar. Varones residentes en Argentina entre 19 y 20 años de edad

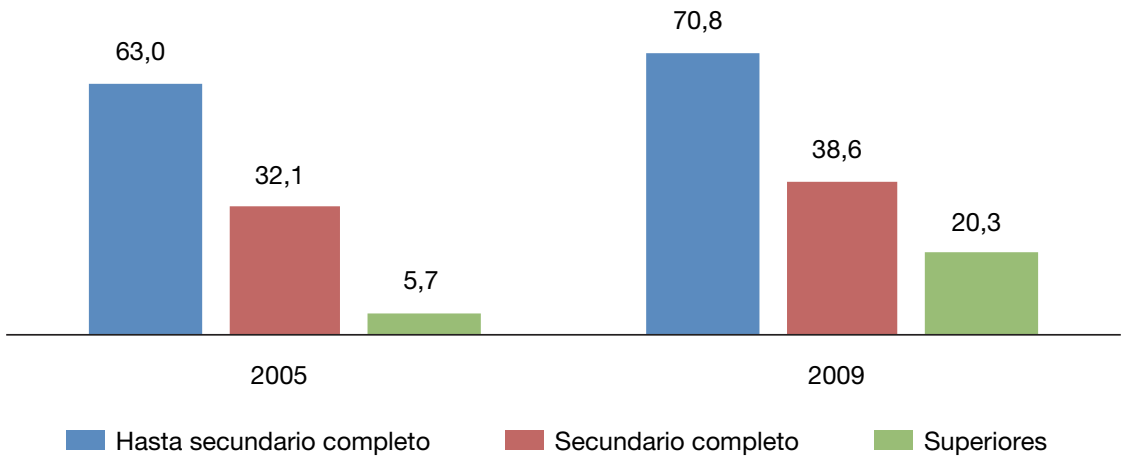

Fuente: microdatos de la Encuesta Permanente de Hogares, 3er trimestre 2005 y 2009 (INDEC).

En una lectura horizontal entre 2005 y 2009, puede verse que el FEA crece en el caso de los varones (gráfico 4), pero en forma llamativa para los que provienen de hogares con nivel superior - universitario y no universitario- completo, lo que no hubiera sido esperable para este clima educativo en el hogar. La dinámica es diferente en el caso de las mujeres (gráfico 5), donde lo que se acentúa es el FEA para quienes provienen de hogares con secundario incompleto. Estos hogares tienen el crecimiento más pronunciado, y aquellas que provienen de hogares cuyo principal responsable tiene nivel superior completo muestran una pequeña reducción. Estas diferencias muestran cómo el nivel educativo y el género interactúan en forma diferencial para el caso argentino, por ello, también se realizará un modelo de análisis similar al español para el caso argentino.

Gráfico 5. Tasas de fracaso escolar administrativo, por año y por nivel de estudios de la persona principal del hogar. Mujeres residentes en Argentina entre 19 y 20 años de edad

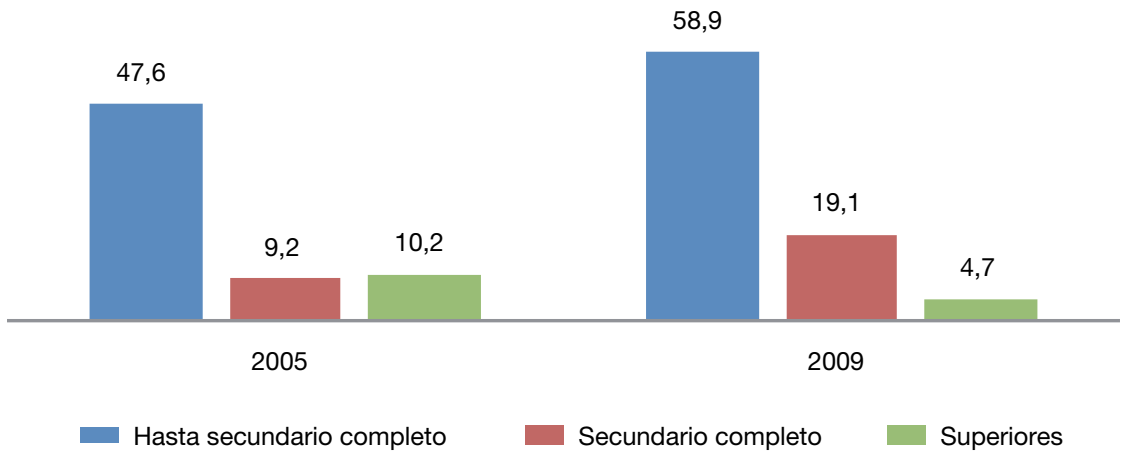

Fuente: microdatos de la Permanente de Hogares, 3er trimestre 2005 y 2009 (INDEC). 


\section{Modelos multivariantes}

Se ha procedido a estimar cuatro regresiones: la primera introduce las variables independientes con las que buscamos capturar el efecto renta (el nivel de paro del hogar) y el efecto sustitución (la tasa de paro de la comunidad autónoma), con las variables de control del origen social, la nacionalidad y el nivel de desarrollo de la comunidad autónoma (tasa de alfabetización en 1960 por comunidad autónoma en España y en promedio para el total del territorio argentino), separando entre hombres y mujeres. El segundo modelo busca detectar si hay variaciones en el nivel de fracaso escolar entre 2007 y 2013, para España, y entre 2005 y 2009 para Argentina, que no se deben a variaciones en los valores medios de las variables independientes del modelo 1. En el tercer modelo, se deja que varíe el efecto de cada variable independiente en el segundo periodo (crisis) con respecto al primero, introduciendo interacciones con dicho año. Es decir, se intenta estimar si hay un cambio estructural, en el sentido de que a lo largo de la crisis el efecto del nivel educativo de la familia sobre el fracaso escolar de los hijos ha cambiado. Y en el modelo cuarto, se añade una interacción de orden tres, entre año, nivel de estudios del sustentador principal y tasa de paro regional, para saber si la crisis puede haber afectado de forma diferente, es decir, se trata de saber si el nivel de paro, una de las formas en las que las familias perciben la crisis, produce efectos distintos en los dos momentos del ciclo económico sobre el nivel de estudios. El individuo de comparación para las variables presentes en la regresión es el modal, es decir, el más frecuente en cada categoría de las variables independientes, por lo cual su efecto se interpreta a partir de dicho individuo. Sus características son las de una persona proveniente de un hogar con estudios post-primarios no universitarios, en el que hay al menos un miembro activo del hogar que no está en paro, español tanto de nacionalidad como de nacimiento, y con referencia en el año 2007.

En el panel 1 y en el panel 2 presentamos los resultados para hombres y mujeres para España, respectivamente. En ambos casos, si seguimos el Criterio de Información Bayesiano (BIC), recomendado para medir la bondad explicativa de los modelos logit, tanto en el caso de los varones como de las mujeres, el modelo 1, el que no tiene en cuenta variaciones temporales, es el que mejor ajusta. Esto quiere decir que el ciclo económico no afecta a la relación entre capital cultural del hogar y fracaso escolar. Las variaciones que observamos a lo largo del ciclo se deben a variaciones en los niveles de paro de las familias o de la región, pero no a que varíe la desigualdad de oportunidades educativas entre hogares por diferencias de nivel en capital cultural. Dicho de manera más intuitiva, si una familia emplea un lenguaje complejo con sus hijos, o les lee por la noche, no porque la economía vaya bien o mal va a variar tanto su patrón de crianza cultural como para que produzca efectos significativos.

Aunque el BIC nos lleva a optar por este primer modelo, también puede ser ilustrativo apreciar qué información nos facilitan los otros modelos, aunque no sean relevantes desde el punto de vista de su riqueza informativa en términos estadísticos bayesianos. Si tenemos en cuenta los parámetros significativos o el 
Panel 1. Resultados de la regresión logística del fracaso escolar administrativo, varones residentes en España entre 19 y 20 años de edad

\begin{tabular}{|c|c|c|c|c|}
\hline Variable & Modelo 1 (M1) & M2: Año 2013 & M3: Interac. año & M4: Interac. año paro \\
\hline Sin estudios & $1,57^{\star \star *}$ & $1,57^{\star \star \star}$ & $1,52^{\star \star *}$ & $1,52^{\star \star \star}$ \\
\hline Primarios & $1,04^{\star \star \star}$ & $1,04^{\star \star \star}$ & $1,00^{\star \star \star}$ & $1,00^{\star \star \star}$ \\
\hline Universitar & $-1,80^{\star \star \star *}$ & $-1,80^{\star \star \star}$ & $-2,46^{\star \star \star}$ & $-2,46^{\star \star \star}$ \\
\hline Parado & $0,41^{\star * *}$ & $0,41^{\star \star \star}$ & $0,40^{\star \star \star}$ & $0,40^{\star \star \star}$ \\
\hline Inmigrante & $0,37^{\star * *}$ & $0,37^{\star \star \star}$ & $0,32^{\star * *}$ & $0,32^{\star \star *}$ \\
\hline Alfab.1960 & $-0,03^{\star \star \star}$ & $-0,04^{\star \star \star}$ & $-0,04^{\star \star \star}$ & $-0,04^{\star \star \star}$ \\
\hline Paro CCAA & $-0,01^{\star \star *}$ & $-0,02^{*}$ & $-0,05^{*}$ & $-0,05^{\star}$ \\
\hline Año 2013 & & 0,14 & (omitida) & (omitida) \\
\hline Sin est ${ }^{\star} 2013$ & & & 0,10 & 0,18 \\
\hline Primar.*2013 & & & 0,08 & $-0,01$ \\
\hline Univer.`2013 & & & $1,16^{\star \star \star}$ & $1,11^{\star *}$ \\
\hline Paro*2013 & & & 0,00 & $-0,08$ \\
\hline Inmig.*2013 & & & 0,09 & 0,10 \\
\hline CAalfb*2013 & & & 0,01 & 0,01 \\
\hline Caparo*2013 & & & 0,04 & 0,04 \\
\hline Paro*sinest13 & & & & $-0,29$ \\
\hline Paro*prim2013 & & & & 0,32 \\
\hline Paro*univ2013 & & & & 0,31 \\
\hline _cons & $1,00^{\star \star *}$ & $1,26^{\star \star}$ & $2,02^{\star \star \star}$ & $2,02^{\star \star \star}$ \\
\hline $\mathrm{N}$ & 15.186 & 15.186 & 15.186 & 15.186 \\
\hline LL & $-5.931,85$ & $-5.931,60$ & $-5.922,29$ & $-5.919,12$ \\
\hline AIC & $11.879,71$ & $11.881,19$ & $11.876,58$ & $11.876,25$ \\
\hline BIC & $11.940,74$ & $11.949,84$ & $11.998,63$ & $12.021,18$ \\
\hline
\end{tabular}

Leyenda: $p<0,1^{*} ; p<0,05^{* *} ; p<0,01^{* * *}$

Fuente: microdatos de la Encuesta de Población Activa (INE)

Criterio de Información de Akaike (AIC), recomendado para evaluar la capacidad predictiva de un modelo, y menos conservador ante el añadido de nuevos parámetros en la estimación, la selección de modelos es diferente (Kuha, 2004). En el caso de los varones, habría que considerar que el nivel de estudios universitarios del sustentador principal produce una mayor reducción del FEA en 2013 que en 2007 (pasa de -1,8 en 2007 a -2,4 en 2013). Este efecto debería ser matizado, pues dado el bajo porcentaje de personas con padre universitario en situación de fracaso escolar, dicho parámetro recoge los efectos no lineales que los modelos logit en las colas de la distribución de probabilidad, donde una pequeña variación de porcentaje absoluto se transforma en un parámetro alto (un parámetro del modelo logit recoge que no entraña la misma dificultad marginal reducir el fracaso escolar en un $1 \%$ cuando es bajarlo del $5 \%$ al $4 \%$, que cuando es bajarlo del 50\% al 49\%), y como vimos en los gráficos 1 y 2 , el porcentaje de jóvenes es muy bajo, por lo que una pequeña variación queda reflejada en un gran cambio en el parámetro del modelo logit. 
Panel 2. Resultados de la regresión logística del fracaso escolar administrativo, mujeres residentes en España entre 19 y 20 años de edad

\begin{tabular}{|c|c|c|c|c|}
\hline Variable & Modelo 1 (M1) & M2: Año 2013 & M3: Interac. año & M4: Interac. año paro \\
\hline Sin estudios & $1,53^{\star \star \star}$ & $1,53^{\star \star \star}$ & $1,44^{\star \star \star}$ & $1,44^{\star \star \star}$ \\
\hline Primarios & $1,06^{\star \star \star}$ & $1,06^{\star \star *}$ & $0,98^{\star \star \star}$ & $0,98^{* * *}$ \\
\hline Univers. & $-1,94^{\star \star \star}$ & $-1,94^{\star \star \star}$ & $-2,48^{\star \star \star}$ & $-2,48^{\star \star \star}$ \\
\hline Parado & $0,57^{\star \star *}$ & $0,57^{\star \star *}$ & $0,68^{\star * *}$ & $0,68^{* * *}$ \\
\hline Inmigrante & $0,41^{\star \star \star}$ & $0,41^{\star \star *}$ & $0,50^{\star \star \star}$ & $0,50^{\star \star \star}$ \\
\hline Alfab. 1960 & $-0,03^{\star \star \star}$ & $-0,03^{\star \star \star}$ & $-0,01$ & $-0,01$ \\
\hline Paro CCAA & $-0,02^{\star \star \star}$ & $-0,01$ & $0,05^{\star \star}$ & $0,05^{\star \star}$ \\
\hline Año 2013 & & $-0,09$ & (omitida) & (omitida) \\
\hline Sin est?2013 & & & 0,23 & 0,09 \\
\hline Primar²013 & & & 0,19 & 0,21 \\
\hline Univer²0132 & & & $0,97^{\star \star}$ & $1,10^{\star \star}$ \\
\hline Paro*2013 & & & $-0,17$ & $-0,17$ \\
\hline Inmig.*2013 & & & $-0,18^{*}$ & $-0,18^{\star}$ \\
\hline CAalfab*2013 & & & $-0,04^{*}$ & $-0,04^{*}$ \\
\hline Caparo*2013 & & & $-0,09^{\star \star \star}$ & $-0,09^{\star \star \star}$ \\
\hline Paro*sinest ${ }^{*} 13$ & & & & 0,38 \\
\hline Paro*prim¹3 & & & & $-0,05$ \\
\hline Paro*univ*2013 & & & & (omitida) \\
\hline _cons & 0,51 & 0,21 & $-2,24^{\star *}$ & $-2,24^{\star *}$ \\
\hline $\mathrm{N}$ & 14.347 & 14.347 & 14.347 & 14.271 \\
\hline LL & $-4.519,81$ & $-4.519,70$ & $-4.504,61$ & $-4.501,29$ \\
\hline AIC & $9.055,62$ & $9.057,41$ & $9.041,21$ & $9.038,59$ \\
\hline $\mathrm{BIC}$ & $9.116,19$ & $9.125,55$ & $9.162,36$ & $9.174,77$ \\
\hline
\end{tabular}

Leyenda: * $p<0,1 ;{ }^{* \star} p<0,05 ;{ }^{* \star *} p<0,01$

Fuente: microdatos de la Encuesta de Población Activa (INE)

En el caso de las mujeres, al efecto positivo del nivel universitario del sustentador principal en 2013, cabe añadir que disminuye su sensibilidad a las condiciones de la comunidad autónoma, tanto a su nivel de desarrollo (interacción entre año y tasa de alfabetización en la comunidad autónoma) como a la incidencia de la crisis (interacción entre año y paro de la comunidad autónoma). Parece, por tanto, que hay cierta tendencia a que las mujeres desarrollen sus estrategias educativas movidas por motivaciones más fuertes que el contexto económico de su lugar de residencia.

Se continúa con el mismo criterio que en el modelo español: utilizar el BIC como criterio principal para elegir el modelo. Se puede observar que el modelo 1 es el que mejor ajusta para los varones; mientras que el modelo 2 hace lo propio para las mujeres. Cabe destacar que en ambos casos lo hace por diferencias poco importantes.

La selección del modelo 1 para los varones indica que los factores culturales y estructurales no varían con el ciclo económico, por lo que la relación entre 
Panel 3. Resultados de la regresión logística del fracaso escolar administrativo, varones residentes en Argentina entre 19 y 20 años de edad

\begin{tabular}{|c|c|c|c|c|}
\hline Variable & Modelo 1 (M1) & M2: Año 2009 & M3: Interac. año & M4: Interac. año paro \\
\hline Sin infor. & $-0,82^{\star \star \star}$ & $-0,81^{\star \star *}$ & $-1,01^{\star \star \star}$ & (omitido) \\
\hline Secundario & $-1,33^{\star \star \star}$ & $-1,35^{\star \star \star}$ & $-1,36^{\star \star \star}$ & (omitido) \\
\hline Superiores & $-2,62^{\star \star \star}$ & $-2,63^{\star \star \star}$ & $-2,39^{\star \star \star}$ & (omitido) \\
\hline Paro del hogar & $0,01^{* *}$ & $0,01^{\star \star}$ & $0,01^{\star *}$ & \\
\hline Inmigración & 0,55 & 0,56 & $-0,19$ & $-0,40$ \\
\hline$\%$ secun aglo. & 0,17 & 0,16 & 0,18 & 0,18 \\
\hline$\%$ paro aglo. & $-0,03$ & $-0,01$ & $-0,02$ & $-0,00$ \\
\hline Año 2009 & & $-0,30^{*}$ & (omitido) & (omitido) \\
\hline Sin info*2009 & & & 0,45 & $0,97^{*}$ \\
\hline Secun.*2009 & & & 0,06 & 0,15 \\
\hline Univ. ${ }^{\star 2} 2009$ & & & $-1,02^{*}$ & $-1,38^{\star *}$ \\
\hline Paro H. ${ }^{\star} 2009$ & & & $-0,00$ & \\
\hline Inmigr.*2009 & & & 1,66 & 1,81 \\
\hline \%Secund ${ }^{\star 2} 009$ & & & $-0,07$ & $-0,06$ \\
\hline Paro aglo.*2009 & & & 0,01 & $-0,01$ \\
\hline ParoHogar 2009 & & & & 0,00 \\
\hline Sinlnfo*Paro*2009 & & & & 0,02 \\
\hline Secund*Paro*2009 & & & & $-0,00$ \\
\hline SuperParo*2009 & & & & 0,02 \\
\hline _cons & 0,31 & 0,25 & 0,23 & 0,21 \\
\hline $\mathrm{N}$ & 1831 & 1831 & 1831 & 1920 \\
\hline LL & $-1.117,13$ & $-1.113,84$ & $-1.107,13$ & $-1.142,25$ \\
\hline AIC & $2.250,26$ & $2.245,68$ & $2.246,25$ & $2.320,50$ \\
\hline $\mathrm{BIC}$ & $2.294,36$ & $2.295,29$ & $2.334,45$ & $2.420,58$ \\
\hline
\end{tabular}

Leyenda: * $p<0,1 ;{ }^{* *} p<0,05:{ }^{* * *} p<0,01$

Fuente: microdatos de la Encuesta Permanente de Hogares (INDEC)

los varones y el fracaso escolar administrativo muestra ciertas constantes y un efecto esperable: las chances de un mayor FEA decrecen cuanto mayor es el nivel educativo del hogar. Hay una valoración cultural importante; mientras que el efecto del desempleo opera en sentido inverso, aumentando las chances de FEA.

Inversamente, en las mujeres el efecto de la crisis se ha sentido con una fuerza relativamente mayor. Aquí predomina el modelo 2, pues resulta significativo el efecto fijo del cambio de año. En todo caso, se registra la misma dinámica en lo referente al capital educativo del hogar y al paro; pero la crisis parece haber disminuido las chances de FEA, lo que sugiere un efecto sustitución.

En conjunto, la situación de Argentina es bastante compleja y desafiante. Pareciera que el efecto sustitución predominara por sobre el efecto renta, y que el efecto de la crisis ha sido positivo para las mujeres, que fracasan menos. Pero este modelo solo ajusta mejor por muy leve margen con respecto al modelo 1. Considerando que el impacto de la crisis en Argentina se debe en 
Panel 4. Resultados de la regresión logística del fracaso escolar administrativo, mujeres residentes en Argentina entre 19 y 20 años de edad

\begin{tabular}{|c|c|c|c|c|}
\hline Variable & Modelo 1 (M1) & M2: Año 2009 & M3: Interac. año & M4: Interac. año paro \\
\hline Sin inforo & $-0,59^{\star}$ & $-0,62^{*}$ & $-0,72^{*}$ & (omitido) \\
\hline Secundario & $-1,81^{\star \star \star}$ & $-1,80^{\star \star \star}$ & $-1,63^{\star \star \star}$ & (omitido) \\
\hline Superiores & $-2,85^{\star \star \star}$ & $-2,89^{\star \star \star}$ & $-3,48^{\star \star \star}$ & (omitido) \\
\hline Paro del hogar & $-0,00$ & $-0,01$ & $-0,01$ & $-0,00$ \\
\hline Inmigración & $-0,07$ & $-0,11$ & $-0,07$ & $-0,26$ \\
\hline \% secun aglo. & $-0,06$ & $-0,06$ & $-0,11$ & 0,03 \\
\hline$\%$ paro aglo & $-0,05^{\star \star}$ & $-0,02$ & 0,04 & $-0,12$ \\
\hline Año 2009 & & $-0,41^{\star *}$ & (omitido) & (omitido) \\
\hline Sin infox2009 & & & 0,23 & $0,97^{\star}$ \\
\hline Secun.x2009 & & & $-0,47$ & 0,15 \\
\hline Univ.x2005 & & & $1,38^{\star}$ & $-0,46$ \\
\hline Paro H×2009 & & & 0,01 & \\
\hline Inmigr.x2009 & & & $-0,12$ & 0,39 \\
\hline \%Secundr2009 & & & 0,06 & $-0,06$ \\
\hline Paro aglo.*2009 & & & $-0,09^{\star *}$ & $-0,01$ \\
\hline Paro*Hogar*2009 & & & & 0,00 \\
\hline Sinlnfo*Paro*2009 & & & & $0,05^{\star \star \star}$ \\
\hline Secund*Paro*2009 & & & & $-0,00$ \\
\hline Super*Paro*2009 & & & & 0,02 \\
\hline _cons & $0,94^{\star \star}$ & $0,82^{*}$ & 0,56 & 0,59 \\
\hline$N$ & 1.737 & 1.737 & 1.737 & 1.816 \\
\hline LL & $-1.014,25$ & $-1.009,09$ & $-999,79$ & $-1.018,82$ \\
\hline AIC & $2.044,49$ & $2.036,18$ & $2.031,58$ & $2.073,65$ \\
\hline $\mathrm{BIC}$ & $2.088,17$ & $2.085,32$ & $2.118,93$ & $2.172,58$ \\
\hline
\end{tabular}

Leyenda: * $p<0,1 ;{ }^{* \star} p<0,05 ;{ }^{* * *} p<0,01$

Fuente: microdatos de la Encuesta Permanente de Hogares (INDEC)

mayor medida a debilidades estructurales de la propia economía nacional, y en menor medida a un shock exógeno internacional, es posible considerar que la diferencia entre géneros no sea tan influyente, y que los factores estructurales asociados a un bajo capital educativo en el stock global y una alta informalidad económica estén pesando más.

\section{Conclusiones}

La evolución del FEA agregado ante la crisis económica en ambos países ha sido diferente, pues en España ha disminuido, mientras que ha aumentado en Argentina, por lo que cabe sugerir que en un país ha dominado el efecto sustitución, y en el otro el efecto renta. Basta una mirada al gráfico 1 para poder inferir que la crisis impactó con mayor fuerza en España, pero sus condiciones de desarrollo y su alta renta permitieron que dominase el efecto sustitución. En 
el caso de Argentina, el impacto de la misma crisis internacional pudo haber sido menor, pero aun así bastó para hacer crecer los índices de FEA, dado que, en Argentina, un deterioro de la economía familiar opera con más fuerza como una restricción a las decisiones de la familia, de lo que parece hacerlo en España, al tiempo que el desempleo, el principal elemento de la reducción del coste de oportunidad de estudiar, no varió. En este sentido, tal y como señala Peña (2013), el efecto de signo contrario de las crisis sobre la demanda de educación puede llevar a agrandar la brecha de desarrollo económico entre países más o menos ricos. Si la crisis aumenta la inversión en capital humano en España pero la reduce en Argentina, cabe esperar que este efecto diferencial se note en el crecimiento económico en el largo plazo.

En cuanto a la desigualdad de oportunidades bruta, puede observarse que ha aumentado en España, por el aumento del fracaso escolar administrativo entre jóvenes de familias sin estudios, mientras que ha disminuido en Argentina entre los varones debido al mayor fracaso escolar de los jóvenes de familias de estudios superiores, mientras que entre las mujeres ha aumentado la desigualdad, por la subida del fracaso entre las jóvenes de familias que no pasan del nivel secundario. Para entender la dinámica social tras estos efectos brutos, se estimaron regresiones logísticas, con las variables de origen social y de paro familiar y territorial, controlando la condición de inmigración, y con regresiones por separado para países y para hombres y mujeres. Se seleccionaron los modelos a partir del BIC y se pudo concluir que estas variaciones brutas no obedecen a cambios estructurales en la relación entre origen social (medido por el nivel de estudios de la persona de referencia del hogar) y fracaso escolar, sino a cómo el efecto renta y el efecto sustitución inciden en el nivel de fracaso escolar de los jóvenes. Las variaciones brutas observadas en la desigualdad de oportunidades se deben, por tanto, a cómo varían las condiciones del mercado durante las crisis, pues, por un lado, hacen a los hogares más pobres, y por otro, hacen a los estudios más atractivos. Pero una vez descontados estos dos efectos, en las regresiones logísticas observamos que ambas crisis no han afectado a cómo el capital cultural impacta sobre la desigualdad de oportunidades educativas.

En Argentina, además, se observa un componente de género claramente diferente en los efectos brutos, del que cabe deducir que el efecto negativo de la crisis lleva a que más varones provenientes de familias de estudios medios y superiores dejen de estudiar, posiblemente para entrar en el sector informal de la economía, mientras que las mujeres de familias sin estudios finalizan en menor medida la etapa obligatoria durante la crisis. Desde el punto de vista neto, la crisis llevó a un menor fracaso escolar en las mujeres argentinas.

Como afirman autores como Carabaña, la existencia de evidencia que señala asociaciones a nivel agregado no implica necesariamente efectos lineales en cada clase social. Este autor señala que, en el caso español, hay elementos acerca de la valoración de la finalización de la educación obligatoria y la cultura del empleo temprano en sectores tales como la construcción. En el caso de Argentina, se podrían considerar futuras indagaciones acerca del funcionamiento del 
mercado informal y su demanda de mano de obra adolescente y joven para empleos de poca productividad pero remuneración inmediata que tienen el efecto de «disuadir» sobre los beneficios de la escolarización (Clemente et al., 2014) o la presión para dedicar tiempo al trabajo doméstico no remunerado en el caso de las mujeres, sobre todo las de clases populares.

Desde el punto de la comparación internacional, debemos destacar que, más allá de la variabilidad institucional y de otros tipos existentes entre países, detectamos ciertas lógicas sociales comunes. Por un lado, en la línea con lo que lleva señalando la sociología de la educación desde hace más de medio siglo, la importancia de las condiciones socioeconómicas y culturales del hogar a la hora de explicar los resultados educativos. Por otro, el efecto de la crisis, al menos en esta comparación, no opera transformando este tipo de relación (no detectamos cambios estructurales relevantes entre los periodos pre y postcrisis), sino por la variación en las oportunidades económicas de la familia y del mercado de trabajo; señalando así la sensibilidad de la demanda de educación a la variación de incentivos y restricciones que suponen los cambios del ciclo económico, y que son ajenas al propio sistema educativo. A su vez, entre las continuidades estructurales, se debe destacar que el mayor desarrollo económico de España se traduce en una mayor capacidad de resistencia de los hogares ante una crisis severa; mientras que, en el caso argentino, la resistencia es menor, incluso ante una crisis moderada para los estándares de dicho país. Debido a que en España la disminución de fracaso escolar se debe en buena medida a las variaciones del mercado de trabajo, si se recupera el empleo juvenil de baja cualificación, cabe esperar que repunte el fracaso escolar, a no ser que tal efecto sea compensado bien por medidas educativas, bien por una disminución de hogares de bajo capital cultural.

\section{Referencias bibliográficas}

BeCCARia, Luis y Groisman, Fernando (2005). «Jóvenes y empleo en la Argentina«». Anales de la Educación común. Tercer siglo, 1 (1-2), 177-182.

- (2015). «Informalidad y segmentación del mercado laboral: el caso de la Argentina». Revista CEPAL 117, 127-143.

BERnARD, P. Yves (2015). Le décrochage scolaire. París: PUF.

Boudon, Raymond (1983). La desigualdad de oportunidades. Barcelona: Laia.

Bourdieu, Pierre (1991). El sentido práctico. Madrid: Taurus.

Busso, Mariana y PÉrez, Pablo (2015). "Combinar trabajo y estudios superiores. ¿Un privilegio de jóvenes de sectores de altos ingresos?». Población y sociedad, 22 (1), 5-29.

CARABAÑA, Julio (2004). «Ni tan grande, ni tan grave, ni tan fácil de arreglar: datos y razones sobre el fracaso escolar». Información Comercial Española, 180, 131-140.

- (2016). "¿Aumentar la escolaridad o fomentar la titulación en Secundaria Superior?». En: A. VV. (ed.). Indicadores comentados sobre el estado del sistema educativo español 2016. Madrid: Fundación Ramón Areces.

- (2018). «¿Menguará la escolarización cuando crezca el empleo?». Revista Española de Sociología, 27 (1), 109-112.

<https://doi.org/10.22325/fes/res.2018.8>. 
ClARK, Damon (2011). «Do recessions keep students in school? The impact of youth unemployment on enrolment in post-compulsory education in England». Economica, 78 (311), 523-45. <https://doi.org/10.1111/j.1468-0335.2009.00824.x>.

Clemente, Adriana; Molina Derteano, Pablo y Roffler, Erika (2014). «Pobreza y acceso a las políticas sociales. El caso de los jóvenes en el conurbano bonaerense». Ciencias Sociales, 86.

Comín, Francisco y Hernández, Mauro (eds.) (2013). Crisis económicas en España 1300-2012. Madrid: Alianza Editorial.

Dejong, Davis e Ingram Beth (2001). «The cyclical behavior of skill acquisition». Review of Economic Dynamics 4(3) 536-561. <https:doi.org/10.1006/redy.2000.0124>.

Dellas, Harris y SAKellaris, Plutarchos (2003). «On the cyclicality of schooling: theory and evidence». Oxford Economic Papers, 55 (1), 148-72. $<$ https://doi.org/10.1093/oep/55.1.148>.

FERnández Mellizo-Soto, María (2015). "Continuidad o cambio en la desigualdad de oportunidades educativas: evidencia internacional y teorías». Revista Española de Sociología, 23, 151-64.

Ferraris, Jorge (2007). Por qué estamos donde estamos. Buenos Aires: Catálogos.

Fiszbein, Ariel; Adúriz, Isidro y Giovagnoli, Paula Inés (2003). «El impacto de la crisis argentina en el bienestar de los hogares». Revista de la CEPAL, 79, $151-167$.

Gottau, Verónica y Moschetti, Mauro (2017). «El sistema educativo argentino. Entre la privatización interna y la privatización abierta: trayectorias divergentes y desigualdades». Cadernos de Pesquisa: Pensamento Educacional, 10 (26), 182-202.

Grimson, Alejandro y Tenti Fanfani, Ernesto (2014). Mitomanias de la educación argentina: critica de las frases hechas, las medias verdades y las soluciones mágicas. Buenos Aires: Siglo XXI.

GutiérReZ, Alicia (2005). Pobre', como siempre: estrategias de reproducción social en la pobreza: un estudio de caso. Córdoba: Ferreyra.

GuTiÉrRez, Gonzalo y UANini, Mónica (2015). «Transformaciones en los procesos de la escolaridad secundaria argentina (1970-2013)». Revista Latinoamericana de Políticas y Administración de la Educación, 2, 28-37. <http://eprints.ucm.es/35644/1/T36807.pdf>.

INE (2005). Encuesta de Población Activa. Metodología de 2005. Madrid.

KATZMAN, Rubén (2005). "Activos, vulnerabilidad y estructuras de oportunidades». Enfoque AVEO. Inclusión social. Una perspectiva para la reducción de la pobreza, 54-77.

KUHA, Jouni (2004). "AIC \& BIC: Comparisons of assumptions and performance». Sociological Methods \& Research, 33 (2), 189-229. <https://doi.org/10.1177/0049124103262065>.

Lacuesta, Aitor; Puente, Sergio y Villanueva, Ernesto (2012). «The schooling response to a sustained increase in low-skill wages: Evidence from Spain 19892009». Documentos de Trabajo. Banco de España.

LEIVAS, Marcela (2017). «Educación secundaria, desigualdad educativa y nuevo desarrollismo en la Argentina post 2001: estructuras que perduran y tendencias que se modifican». Revista Mexicana de Investigación Educativa, 22 (72), 57-88.

MARCHESI, Álvaro (2003). El fracaso escolar en España. Fundación Alternativas. <http://www.falternativas.org/base/download/024f_29-07-05_11_2003.pdf>. 
MARTín, María (2018). «Inclusión y equidad: un análisis con base en el acceso y logros para el nivel medio de educación en Argentina». Semestre Económico, 20 (43), 11-138.

MARTíneZ GARCía, J. S. (2004). "Distintas aproximaciones a la elección racional». Revista Internacional de Sociología, 62 (37), 139-173. $<$ https://doi.org/10.3989/ris.2004.i37>.

- (2011). "Género y origen social: diferencias grandes en fracaso escolar y bajas en rendimiento educativo». Revista de la Asociación de Sociología de la Educación, 4 (3), 270-285.

- (2012). «Fracaso escolar y comunidades autónomas». En: Puelles, M. de (ed.). El fracaso escolar en el Estado de las Autonomías. Madrid: Wolters Kluwer.

- (2016). «Crisis y desigualdad de oportunidades educativas». Organización y Gestión Educativa, 24 (5), 9-13.

- (2017a). «El habitus. Una revisión analítica». Revista Internacional de Sociología, 75 (3), e067. <http://dx.doi.org/10.3989/ris.2017.75.3.15.115>.

- (2017b). La equidad y la educación. Madrid: La Catarata.

- (2019). «La educación y la desigualdad de oportunidades educativas en tiempo de crisis». En: VIII Informe FOESSA. Madrid: Cáritas.

Miyar-Busto, María (2017). «La dedicación a los estudios de los jóvenes de origen inmigrante en España en la Gran Recesión». REIS, 157, 123-140. <https://doi.org/10.5477/cis/reis.157.123>.

Molina Derteano, Pablo (2007). «Sueños del eterno retorno de la sociedad salarial para los jóvenes asalariados precarios en condiciones de segmentación territorial». En: SAlviA, A. y CHÁvez Molina, E. (comps.). Sombras de una marginalidad fragmentada. Aproximaciones a la metamorfosis de los sectores populares de la Argentina. Buenos Aires: Miño y Dávila.

- (2012). «Primeras exploraciones hacia las estratificaciones juveniles. Los grandes aglomerados urbanos de Argentina entre 2003 y 2011». Revista Contextualizaciones Latinoamericanas, 4, 2007-2120.

- (en prensa). «El Dotor del Siglo XXI. Logros educativos y condiciones de origen en la Ciudad Autónoma de Buenos Aires». En: Chavéz Molina, Eduardo (comp.).

Molina Derteano, Pablo y DÁvolos, Patricia (en prensa). Las desigualdades regionales y según el hogar de origen en los accesos y logros educativos en la Argentina reciente. CEC/UNICEF.

NúNEEZ, Pedro y LiTiCHEVER, Lucila (2016). «Ser joven en la escuela: temporalidades y sentidos de la experiencia escolar en la Argentina». Psicoperspectivas, 15 (2), 90-101.

PAZ, Jorge (2014). «Pobreza multidimensional en la Argentina. Asimetrías regionales (parte I)». Documentos de Trabajo, 11.

<http://www.economicas.unsa.edu.ar/ielde/items_upload/WPIelde_Nro_11.pdf>.

PEÑA, Pablo A. (2013). «Choques agregados e inversión en capital humano. El logro educativo superior durante la década perdida en México». El Trimestre Económico, $80,113-42$.

Puiggrós, Adriana (2014). «Educación y sociedad en América Latina de fin de siglo: del liberalismo al neoliberalismo pedagógico». Estudios Interdisciplinarios de América Latina y el Caribe, 10 (1).

Rivas, Axel y DBORKIN, Daniela (2018). «¿Qué cambió en el financiamiento educativo en Argentina?». Documento de Trabajo, 162, CIPPEC. 
Rocha, Stella Maris (2016). «Una política para la educación secundaria en la Ciudad de Buenos Aires: de un proyecto democratizador a una escuela reproductora». REXE-Revista de Estudios y Experiencias en Educación, 1 (1), 29-54.

Rodríguez, Juan Carlos y LACASA, José Manuel (2018). «Ciclos económicos, coste de oportunidad y decisión de estudiar: unas hipótesis y una evidencia comparada ilustrativa». Revista Española de Sociología, 27 (1), 113-124. <https://doi.org/10.22325/fes/res.2018.7>.

RUjAS, Javier (2015). Sociología del «fracaso escolan» en España. Doctor, Universidad Complutense, Madrid.

<https://eprints.ucm.es/35644/1/T36807.pdf>.

Salvia, Agustín (2000). «Condiciones de vida y estrategias económicas de los hogares bajo los cambios estructurales». Cuadernos del CEPED, 4. $<$ https://www.aacademica.org/agustin.salvia/52>.

SÁNCHEZ, Yuliana Gabriela (2018). "Jóvenes y sector informal en el Estado de México. Un grupo en desventaja». Perspectivas Sociales, 19 (2), 1-23.

Sebastián, Miguel (2015). La falsa bonanza. Península.

SiEVERTSEN, Harris (2012). «On the cyclicality of school enrollment. Who, what, and for how long?». <http://www.hha.dk/nat/helena/workshop0113/Sievertsen.pdf >.

- (2016). "Local unemployment and the timing of post-secondary schooling». Economics of Education Review, 50, 17-28. <https://doi.org/10.1016/j.econedurev.2015.11.002>.

TARABInI, Aina; Curran, Marta y FonTdEVIla, Clara (2015). «El habitus institucional: una herramienta teórica y metodológica para el estudio de la cultura escolar». Tempora, 18, 37-58.

TorchE, Florencia (2010). «Economic crisis and inequality of educational opportunity in Latin America». Sociology of Education, 83 (2), 85-110. <https://doi.org/10.1177/0038040710367935>.

Torrado, Susana (1981). «Sobre los conceptos de 'estrategias familiares de vida' y 'preoceso de reproducción de la fuerza de trabajo': Notas teórico-metodológicas». Demografía y Economía, 15 (2), 204-233.

VeZub, Lea Fernanda y GARABITO, María Florencia (2017). «Los profesores frente a la nueva/vieja escuela secundaria argentina». Revista Electrónica de Investigación Educativa, 19 (1), 123-140.

<https://doi.org/10.24320/redie.2017.19.1.1096>. 
